\title{
CARACTERIZAÇÃO DO QUEIJO DO MARAJÓ TIPO CREME EM DUAS ESTAÇÕES DO ANO: ASPECTOS FÍSICO-QUÍMICOS E MICROBIOLÓGICOS
}

\section{Characterization of Marajó cheese, cream type, in two seasons: Physicochemical and microbiological aspects}

\begin{abstract}
Vitória Nazaré Costa Seixas ${ }^{1}$, Mayara Rocha Félixl, Guilherme Mendes da Silval, Ítalo Tuler Perrone ${ }^{1 *}$, Renata Golin Bueno Costa ${ }^{2}$, Antonio Fernandes de Carvalho ${ }^{1}$
\end{abstract}

\section{RESUMO}

O queijo do Marajó é um produto artesanal derivado do leite de búfala produzido na Ilha de Marajó (PA). Os objetivos desta pesquisa foram caracterizar por meio de análises físico-químicas e microbiológicas o queijo do Marajó tipo creme e o efeito da estação do ano. $\mathrm{O}$ pH, a porcentagem de gordura no extrato seco (GES) e teor de cloreto de sódio foram atributos de composição centesimal que apresentaram diferença significativa ao nível de $5 \%$ de probabilidade pelo teste Tukey entre as duas estações do ano. Não foi verificada diferença estatística nos percentuais de acidez titulável, umidade, gordura, cinzas, extrato seco total (EST), proteínas e atividade de água. Quanto às características microbiológicas, houve melhoria nos resultados na estação seca com relação à coliformes e Staphylococcus aureus. Entretanto, o resultado de Escherichia coli mostrou-se melhor no período chuvoso, com todas as amostras atendendo o padrão da legislação. Na contagem de aeróbios mesófilos não houve diferença entre os períodos do ano. Não foi detectada a presença dos patógenos Listeria monocytogenes e Salmonella sp. no queijo do Marajó tipo creme nas duas estações do ano. A variabilidade ocorrida no pH, \% GES e $\mathrm{NaCl}$, entre as estações do ano, demonstra a necessidade de maior controle da produção visando a padronização e a manutenção da identidade do produto. Quanto aos padrões microbiológicos, esses estiveram em concordância com estabelecidos pela legislação vigente.

Palavras-chave: queijo artesanal; composição centesimal; qualidade; sazonalidade.

1 Universidade Federal de Viçosa (UFV), Departamento de Tecnologia de Alimentos, Av. P.H. Rolfs, Campus Universitário, 36570-000, Viçosa, MG, Brasil. E-mail: italo.perrone@ufv.br

2 Empresa de Pesquisa Agropecuária de Minas Gerais (EPAMIG), Instituto de Laticínios Cândido Tostes (EPAMIG/ILCT), Juiz de Fora, MG, Brasil.

* Autor para correspondência.

Recebido / Received: 11/07/2013

Aprovado / Approved: 20/11/2013 


\begin{abstract}
The Marajó cheese is an artisanal product derived from buffalo milk produced in Marajó Island-PA. The objectives of this research were to characterize through physicochemical and microbiological the Marajó cheese, cream type, and the effect of the season. The $\mathrm{pH}$, the percentage of fat in dry matter and content of sodium chloride were attributes that proximate composition showed significant difference at $5 \%$ probability by Tukey test between the two seasons. Statistical difference was not found in the percentage of titratable acidity, moisture, fat, ash, total solids extract, proteins and water activity. As for microbiological characteristics, in general, there was an improvement in the results in the dry season as to coliformes and Staphylococcus aureus. However, the result of Escherichia coli has proved to be better in the rainy season, with all samples meeting the standard of legislation. On the count of aerobic mesophilic there was no difference between the periods of the year. The pathogens Listeria monocytogenes and Salmonella sp. were not detected in the Marajó cheese, cream type, within the four seasons of the year. The variability occurred in $\mathrm{pH}, \% \mathrm{NaCl}$, GES and, between seasons, demonstrates the need for greater control of production aimed at standardizing and maintaining the identity of the product. Regarding the microbiological, standards were established in accordance with the current legislation.
\end{abstract}

Keywords: artisanal cheese; centesimal composition; quality; seasonality.

\section{INTRODUÇÃO}

O último Censo Agropecuário apresentou crescimento da bubalinocultura brasileira. O efetivo do rebanho bubalino é de 1.146.798 cabeças, sendo distribuído pelas cinco regiões do país, da seguinte forma: $64,5 \%$ no Norte; $13 \%$ no Sul; $9,12 \%$ no Sudeste; $9,08 \%$ no Nordeste e $4,5 \%$ CentroOeste. Do contingente bubalino da Região Norte, $50 \%$ encontram-se distribuídos entre os municípios da Ilha de Marajó (PA). A microrregião de Arari concentra a maior produção de leite e queijo fabricado com leite de búfala (IBGE, 2006).

A criação de búfalos destaca-se por ser uma atividade capaz de incluir pequenos produtores no cenário produtivo, já que esses animais apresentam capacidade de sobreviver em locais inóspitos aos bovinos e docilidade. Seus derivados apresentam valor agregado e maior rendimento industrial em relação ao leite bovino (VIEIRA et al., 2011).
O produto artesanal típico da região da Ilha de Marajó, oriundo da produção familiar de derivados do leite de búfala, o "queijo do Marajó" também é denominado de queijo Marajó, queijo do Marajó ou requeijão Marajoara. Esse queijo artesanal pode ser produzido por dois processos diferentes, diferenciando-o no tipo creme e o tipo manteiga, com grande aceitação regional (BITTENCOURT, 2011)

O Queijo do Marajó tipo creme tem como principal matéria-prima o leite de búfala, não pasteurizado, que algumas vezes é complementado com leite bovino (BENDELACK, 2004). Queijos fabricados a partir de leite cru possuem uma diversificada e rica microbiota autóctone e sua qualidade depende, em grande parte, da composição dessa microbiota, que influencia na qualidade sensorial do queijo (MARINO et al., 2003).

$\mathrm{Na}$ fabricação do requeijão do Marajó tipo creme, o leite desnatado é submetido à 
coagulação natural com formação da coalhada, a qual é aquecida no soro e posterior dessoragem até que se torne consistente. A massa do queijo é submetida a lavagens com água a diferentes temperaturas e no final com leite desnatado a, aproximadamente, $80^{\circ} \mathrm{C}$, com o objetivo de aumentar seu rendimento (LOURENÇO et al., 2002; BITTENCOURT, 2011).

O queijo do Marajó possui massa compacta, formato cilíndrico ou retangular apresenta textura macia, superfície externa com coloração amarelo-esverdeada e parte interna com cor branca e aroma agradável, sendo levemente ácido e salgado (LOURENÇO, 1999). Seu consumo é imediato em pedaços, fatias ou utilizado em sanduíches, pastéis e outras preparações. Apresenta-se embalado em papel manteiga ou em embalagens plásticas, de 250 g e 500 g, vendido em supermercados, padarias, lanchonetes, restaurantes, feiras livres e hotéis (BENDELACK, 2004).

A Ilha de Marajó possui o maior rebanho bubalino do Brasil, contudo o governo e os produtores não garantiram os investimentos necessários para o beneficiamento adequado da produção leiteira. A falta de infraestrutura, padronização da produção, capacitação de pessoas e técnicas de manuseio adequadas, dificultam o desenvolvimento da atividade no Marajó (BLASKOVSKY et al., 2010).

O objetivo do presente estudo foi caracterizar por meio de análises físico-químicas e microbiológicas o queijo marajoara tipo creme e verificar se há diferença dessas características entre as estações do ano, chuvosa e seca.

\section{MATERIAL E MÉTODOS}

Foram coletadas 22 amostras de queijos do Marajó tipo creme obtido de sete produtores de queijos, escolhidos de acordo com a disponibilidade dos produtos à venda, provenientes dos municípios de Soure e Salvaterra, na Ilha de Marajó (PA). Os queijos foram elaborados com leite de búfala e misturas com leite de vaca, fabricado de maneira artesanal na própria região. As amostras foram coletadas nos pontos de venda, sendo 11 amostras na estação chuvosa, março a abril de 2012 e 11 amostras na estação seca, setembro a outubro de 2012.

Denomina-se de estação chuvosa ou mais chuvosa os meses compreendidos de dezembro a maio, regionalmente chamado de inverno, com maiores índices pluviométricos entre fevereiro a abril. Já a estação seca ou menos chuvosa corresponde ao período entre junho a novembro, conhecida como verão. Essa estação apresenta os menores índices pluviométricos entre setembro e novembro.

As amostras coletadas foram mantidas em suas embalagens originais de venda, armazenadas e transportadas em recipientes isotérmicos com gelo reciclável e mantidas sob refrigeração até o momento das análises físico-químicas e microbiológicas.

\section{Análises físico-químicas}

Foram avaliadas as características físicoquímicas referentes à acidez titulável em percentual de ácido láctico $\left(\% \mathrm{~m} \cdot \mathrm{v}^{-1}\right), \mathrm{pH}$ (método potenciométrico), umidade (secagem em estufa), cinzas totais (incineração em mufla), proteínas (método de Kjeldahl) e gordura (método butirométrico de Gerber para queijo), atividade de água (medidor digital AquaLab marca DecagonDevices ${ }^{\circledR}$ ). A determinação do teor de gordura no extrato seco foi realizada de modo indireto, por meio da razão entre o teor de gordura e o teor de extrato seco total do queijo. As metodologias descritas foram realizadas conforme Brasil (2006). Todas as análises foram feitas em duplicatas.

\section{Análises microbiológicas}

\section{Enumeração de indicadores higiênicos}

Utilizou-se métodos rápidos Petrifilm ${ }^{\circledR} \mathrm{AC}$, EC e Staph Express (3M Microbiology, St. Paul, $\mathrm{MN}, \mathrm{USA}$ ) de acordo com as recomendações 
do fabricante para enumerar, respectivamente, aeróbios mesófilos, coliformes, Escherichia coli (WEHR; FRANK, 2004). A determinação de Staphylococcus aureus coagulase positiva foi realizada de acordo com a AOAC (2001).

Foram pesadas em sacos plásticos esterilizados 25 gramas de diferentes partes dos queijos. Com isso, foram feitas diluições na proporção de 1:10 com $225 \mathrm{~mL}$ de solução salina Peptonada $0,85 \% \mathrm{~m} \cdot \mathrm{v}^{-1}$. As amostras foram homogeneizadas em Stomacher por, aproximadamente, 1 minuto e então realizaram diluições seriadas de até $10^{-8}$.

$\mathrm{Na}$ análise de coliformes e E. coli placas de Petrifilm ${ }^{\circledR} \mathrm{EC}$ contendo alíquotas de $1 \mathrm{~mL}$ das diluições $10^{-1}, 10^{-2}$ e $10^{-3}$ foram incubadas a $35^{\circ} \mathrm{C}$ por 24 e 48 horas, respectivamente. Para aeróbios mesófilos, placas com diluições, $10^{-5}, 10^{-6}, 10^{-7}$ e $10^{-8}$ foram incubadas a $35^{\circ} \mathrm{C}$ durante 48 horas. Para a contagem de Staphylococcus aureus as diluições plaqueadas foram de $10^{-1}, 10^{-2}, 10^{-3}$, $10^{-4}, 10^{-5}, 10^{-6}$ e $10^{-7}$ e a incubação foi feita a $35^{\circ} \mathrm{C}$ por 24 horas.

\section{Pesquisa de Listeria monocytogenes}

A detecção de Listeria sp. foi realizada utilizando metodologia preconizada pela ISO 11290-1 (2004). Homogeneizou-se 25 gramas de cada amostra assepticamente em $225 \mathrm{~mL}$ de caldo para enriquecimento de Listeria (LEB) com incubação a $30^{\circ} \mathrm{C}$ durante 16 a 20 horas. Após o período de incubação, alíquotas de $0,1 \mathrm{~mL}$ foram transferidas para tubos de ensaio contendo $10 \mathrm{~mL}$ de caldo Fraser, incubados a $37^{\circ} \mathrm{C}$ durante 24 horas. Decorrido o tempo de incubação, alíquotas deste caldo foram semeados em ágar Oxford ${ }^{\circledR}$ e Palcam ${ }^{\circledR}$, incubados a $37^{\circ} \mathrm{C}$ durante 24 a 48 horas. Das placas com crescimento típico de Listeria sp, selecionou-se cinco colônias que foram semeadas em ágar TSA-YE e incubadas a $30^{\circ} \mathrm{C}$ durante 24 a 48 horas. Após esse procedimento, as culturas obtidas foram submetidas às provas bioquímicas de catalase, motilidade, $\beta$-hemólise e teste de fermentação da dextrose, xilose, ramnose e manitol.

\section{Pesquisa de Salmonella sp.}

A detecção de Salmonella foi realizada de acordo com a metodologia ISO 6579 (2008). Foram homogeneizados 25 gramas de cada amostra em $225 \mathrm{~mL}$ de salina peptonada tamponada $1 \%$ (APT) e incubadas a $36^{\circ} \mathrm{C}$ por 16 a 20 horas (pré-enriquecimento). Posteriormente, $1 \mathrm{~mL}$ e $0,1 \mathrm{~mL}$ foram transferidos do pré-enriquecimento para tubos contendo $10 \mathrm{~mL}$ de caldo Tetrationato e caldo Rappaport, respectivamente, e incubados a $41^{\circ} \mathrm{C}$ em banho-maria durante 24 a 30 horas. Após o período de incubação, os caldos foram semeados nos ágares XLD e MLCB com incubação a $36^{\circ} \mathrm{C}$ por 18 a 24 horas. Colônias suspeitas foram semeadas em ágar TSI e LIA e incubadas a $36^{\circ} \mathrm{C}$ durante 18 a 24 horas. Os tubos que apresentaram resultados positivos típicos destes ágares passaram para a etapas das provas bioquímicas, com a realização do teste IMViC e produção de urease.

\section{Análise Estatística}

Empregou-se a análise de variância (ANOVA) para os resultados das análises físico-químicas e microbiológica dos produtos com as médias comparadas entre as estações do ano, pelo teste de Tukey a 5\% de probabilidade, através do software Statística, versão 7.0. As análises microbiológicas foram analisadas de forma descritiva.

\section{RESULTADOS E DISCUSSÃO}

\section{Caracterização físico-química}

Os resultados das análises físico-químicas (Tabela 1 e 2) permitiram classificar o queijo do Marajó tipo creme como de média umidade (queijo de massa semidura). Houve duas classificações de acordo com a estação 
do ano na chuvosa, foram classificados como extra gordo (\% GES mínimo de $\left.60 \% \mathrm{~m} \cdot \mathrm{m}^{-1}\right) \mathrm{e}$ na estação seca como gordo (\% GES ente 45 e $\left.59,9 \% \mathrm{~m} \cdot \mathrm{m}^{-1}\right)$, conforme a Portaria n. 146 (BRASIL, 1996).

O queijo do Marajó tipo creme, também chamado de requeijão do Marajó, não atendeu aos quesitos físico-químicos de GES (\%) da legislação Estadual, Portaria no 418 (PARÁ, 2013) na estação chuvosa. Também, nos dois períodos do ano analisados, o queijo do Marajó tipo creme não se enquadrou no Regulamento Técnico para Fixação de Identidade e Qualidade do Requeijão (BRASIL, 1997) (Tabela 1). Provavelmente, o elevado teor de gordura possa estar relacionado com a elaboração do queijo, a partir de leite de búfala que é mais rico em gordura.(variando em torno de $5,5$ e $8,5 \%)$.

O teor de umidade $\left(\% \mathrm{~m} \cdot \mathrm{m}^{-1}\right)$ apresentou-se de acordo ao preconizado pela legislação estadual (ADEPARÁ, 2013) e nacional (BRASIL, 1997) em ambas as estações do ano, chuvosa e seca.

$\mathrm{O} \mathrm{pH}, \%$ GES e teor de cloreto de sódio $(\mathrm{NaCl})$ foram as características físico-químicas que apresentaram diferença significativa a $5 \%$ pelo teste de Tukey entre as duas estações do ano, chuvosa e seca. Por outro lado, não foi verificada diferença significativa nos percentuais de acidez titulável, umidade, gordura, cinzas, EST, proteínas e atividade de água nos dois períodos (Tabela 2).

Os valores médios de extrato seco total dos queijos estão de acordo com trabalhos da literatura (FIGUEIREDO et al., 2011;
BITTENCOURT, 2011; SOUSA et al., 2002; LOURENÇO, 1999).

O percentual médio de gordura nas duas estações do ano não diferiu, estatisticamente. Entretanto, observa-se o alto valor de desvio padrão, principalmente, na estação chuvosa (Tabela 2) o que pode indicar maior variabilidade do teor de gordura. Sugere-se a falta de critérios na fabricação dos queijos analisados, provavelmente, a variação seja devido à mistura de creme de leite bubalino e de leite bovino durante o processamento o que leva a uma diluição da gordura no queijo. Esta observação sugere a necessidade de uniformização da técnica de produção.

Ao comparar com a literatura (Tabela 3 ), o valor de gordura deste estudo encontrado na estação seca foi semelhante de Figueiredo et al. (2011) e na estação chuvosa com Sousa et al. (2002). Diferentemente dos demais autores, os teores encontrados nesta pesquisa foram maiores de que os de Bittencourt (2011); Lourenço (1999) e um dos achados por Sousa et al. (2002).

Quanto ao GES (\%) houve diferença estatística a $5 \%$ de probabilidade pelo teste Tukey, ao contrário do teor de gordura que não apresentou efeito significativo. Ao comparar os resultados da GES com a legislação (Brasil, 1996) houve duas classificações de acordo com a estação do ano, sendo que na chuvosa, 81,82\% classificaram-se como extra gordo, enquanto que na estação seca $72,73 \%$ como gordo.

Segundo Araújo et al. (2011); Matos (2007); Amaral et al. (2005); Schroeder et al. (2004), a porcentagem de gordura no leite de búfala é alta quando comparada com

Tabela1 - Comparação dos requisitos de composição centesimal de requeijão

\begin{tabular}{|c|c|c|c|c|c|}
\hline \multirow[b]{2}{*}{ Requisito (\%) } & \multirow[b]{2}{*}{$\begin{array}{l}\text { Presente } \\
\text { Pesquisa }\end{array}$} & \multirow[b]{2}{*}{$\begin{array}{c}\text { Legislação } \\
\text { Estadual } \\
\text { (PARÁ, 2013) }\end{array}$} & \multicolumn{3}{|c|}{ Padrão da Legislação (BRASIL, 1997) } \\
\hline & & & $\begin{array}{l}\text { Requeijão } \\
\text { cremoso }\end{array}$ & $\begin{array}{l}\text { Requeijão } \\
\text { de manteiga }\end{array}$ & Requeijão \\
\hline GES & 66,55 e 57,48 & Máx. 65,0 & 45,0 a 54,9 & Mín.55,0 & Mín.25,0a59,9 \\
\hline Umidade & 43,06 e 41,00 & 35,0 a 50,0 & Máx. 60,0 & Máx.65,0 & Máx.58,0 \\
\hline
\end{tabular}


outras espécies, sendo variável em função da raça, idade, das regiões onde se encontram os animais, fatores climáticos, como estação do ano, alimentação e período de lactação. A estação chuvosa na Ilha de Marajó coincide com a maior oferta de forragem, maior conforto térmico pela temperatura mais amena, fatores que alteram as respostas fisiológicas dos animais e interferem no desempenho produtivo. Entretanto, nesse período, os animais encontram-se no final do período de lactação com um aumento na concentração de gordura.

De acordo com Silva et al. (2010), a concentração de sólidos totais é maior em animais que estão a mais de 210 dias em lactação, período característico da fase final da secreção do leite.

O percentual de GES apresentou-se acima daqueles descritos na literatura: Figueiredo et al. (2011); Bittencourt (2010); Lourenço (1999) e Sousa et al. (2002) (Tabela 3).

As médias, nas duas estações do ano, dos percentuais de acidez titulável encontrados nesse estudo estiveram abaixo do valor determinado por Bittencourt (2011) (Tabela 3), que encontrou diferença significativa a 5\% entre os períodos do ano, sendo que o período chuvoso apresentou maiores valores para a acidez titulável nos queijos.

Em contrapartida (Tabela 3) este atributo foi superior ao determinado em outros estudos (FIGUEIREDO et al., 2011; SOUSA et al., 2002).

Segundo Queiroga et al. (2009) o padrão de acidez titulável em queijos artesanais pode ser facilmente modificado dependendo da contagem de bactérias lácteas presentes no meio. Esses microrganismos podem fermentar a lactose, resultando em ácido láctico com aumento da acidez titulável.

Os valores de $\mathrm{pH}$ determinados nesta pesquisa foram menores que os encontrados por Bittencourt (2011) e Lourenço (1999) na estação chuvosa e maior na seca (Tabela 3 ).

A umidade dos queijos foi classificada como de média umidade de acordo com a legislação (BRASIL, 1996). Essa umidade

Tabela 2 - Análise físico-química dos queijos do Marajó tipo creme em duas estações do ano

\begin{tabular}{|c|c|c|c|c|c|c|}
\hline \multirow{3}{*}{ Análises (\%) } & \multicolumn{6}{|c|}{ Estação do Ano } \\
\hline & \multicolumn{3}{|c|}{ Chuvosa } & \multicolumn{3}{|c|}{ Seca } \\
\hline & Média $\pm \mathrm{DP}^{*}$ & Mín.* & Máx.* & Média \pm DP* & Mín.* & Máx.* \\
\hline $\begin{array}{l}\text { Acidez titulável } \\
\text { (\% ácido láctico) }\end{array}$ & $0,35 \pm 0,13^{a}$ & 0,20 & 0,59 & $0,32 \pm 0,05^{\mathrm{a}}$ & 0,26 & 0,40 \\
\hline $\mathrm{pH}$ & $4,89 \pm 0,20^{\mathrm{b}}$ & 4,50 & 5,09 & $5,58 \pm 0,24^{\mathrm{a}}$ & 5,17 & 5,91 \\
\hline Umidade & $43,06 \pm 3,23^{a}$ & 36,70 & 47,24 & $41,00 \pm 2,63^{\mathrm{a}}$ & 37,03 & 46,55 \\
\hline Gordura & $38,05 \pm 6,25^{\mathrm{a}}$ & 27,75 & 49,50 & $33,98 \pm 3,50^{\mathrm{a}}$ & 25,25 & 38,25 \\
\hline Proteína Total & $18,65 \pm 1,78^{\mathrm{a}}$ & 16,31 & 21,56 & $19,78 \pm 1,11^{\mathrm{a}}$ & 17,71 & 21,28 \\
\hline Cinzas & $1,60 \pm 0,50^{\mathrm{a}}$ & 1,31 & 3,03 & $1,68 \pm 0,2^{\mathrm{a}}$ & 1,29 & 1,99 \\
\hline EST & $56,94 \pm 3,23^{\mathrm{a}}$ & 52,76 & 63,30 & $59,0 \pm 2,63^{a}$ & 53,45 & 62,97 \\
\hline GES & $66,55 \pm 7,81^{\mathrm{a}}$ & 50,51 & 78,20 & $57,48 \pm 4,22^{b}$ & 47,24 & 63,23 \\
\hline Sal (NaCl) & $0,45 \pm 0,23^{b}$ & 0,25 & 1,01 & $0,66 \pm 0,15^{\mathrm{a}}$ & 0,29 & 0,86 \\
\hline $\begin{array}{l}\text { Atividade de } \\
\text { água (aw) }\end{array}$ & $0,982 \pm 0,006^{\mathrm{a}}$ & 0,970 & 0,990 & $0,980 \pm 0,003^{\mathrm{a}}$ & 0,971 & 0,983 \\
\hline
\end{tabular}

* DP: Desvio Padrão; Min*: mínimo; Máx.*: Máximo

Médias seguidas pela mesma letra não diferem significativamente entre si pelo teste de Tukey $(\mathrm{p}>0,05)$. 
está de acordo com trabalhos realizados com o queijo do Marajó tipo creme (FIGUEIREDO et al., 2011; BITTENCOURT, 2011; SOUSA et al., 2002; BENDELAK, 2004; LOURENÇO, 1999) (Tabela 3).

De acordo com Ide; Benedet (2001), as variações nos teores de umidade podem estar ligadas à forma de produção, à quantidade e tipo de salga, bem como a pressão exercida no momento da prensagem do queijo.

Valores de cinzas e EST não diferiram, estatisticamente, com os dois períodos do ano analisado e podem ser relacionados à constância de concentração média dos atributos teor de umidade, gordura e proteína. Embora tenha sido observada diferença na concentração de sal nas duas estações, essa não foi suficiente para alterar os valores de cinzas e EST.

O percentual de cinzas apresentou-se semelhante aos determinados nos trabalhos de Sousa et al. (2006) e Lourenço (1999), contudo valores mais elevados foram descritos por Figueiredo et al. (2011) e Bittencourt (2011).

Os valores de proteína total não diferiram com a estação do ano assim como o teor de gordura, podendo estar associado à prática da mistura de leite de búfala com o de vaca. Os teores de proteínas observados neste trabalho foram semelhantes aos determinados por Figueiredo et al. (2011), Bittencourt (2011) e Lourenço (1999), em contrapartida diferiram dos encontrados por Sousa et al. (2002).

De acordo com a Tabela 2 observa-se que o pH e a concentração de cloreto de sódio variam significativamente com a estação do ano, sendo que os valores mais elevados destes atributos ocorrem na estação seca. É possível estabelecer uma relação tecnológica entre o pH da massa e a concentração de $\mathrm{NaCl}$. Segundo Van Dender; Gallina (2006), o processo físico-químico de fusão de queijo processado na presença de agentes fundentes é descrito como uma seqüência de reações que ocorrem simultaneamente: remoção do cálcio do sistema proteico, solubilização ou peptização e dispersão da proteína, hidratação ou intumescimento, estabilização do $\mathrm{pH}$ e formação de uma nova estrutura proteica durante o resfriamento. As mesmas autoras afirmam ainda que a modificação que ocorre na estrutura do coágulo original durante o processo de fusão é dada principalmente pela remoção dos íons de cálcio das micelas de caseína sob

Tabela 3 - Resultados das médias das análises físico-químicas do queijo do Marajó tipo creme com resultados de outros autores

\begin{tabular}{|c|c|c|c|c|c|c|}
\hline \multicolumn{7}{|c|}{ Literatura } \\
\hline Análises (\%) & $\begin{array}{l}\text { Presente } \\
\text { pesquisa }\end{array}$ & $\begin{array}{l}\text { Figueiredo } \\
\text { et al. (2011) }\end{array}$ & $\begin{array}{l}\text { Bittencourt } \\
\quad(2011)\end{array}$ & $\begin{array}{l}\text { Bendelak } \\
\text { (2004) }\end{array}$ & $\begin{array}{c}\text { Sousa } \\
\text { et al.(2002) }\end{array}$ & $\begin{array}{l}\text { Lourenço } \\
\text { (1999) }\end{array}$ \\
\hline $\begin{array}{l}\text { Acidez titulável } \\
\text { (\% ácido láctico) }\end{array}$ & $0,35 / 0,35$ & 0,18 & 0,62 & - & 0,16 a 0,20 & - \\
\hline $\mathrm{pH}$ & $4,89 / 5,58$ & - & 5,15 & - & - & 5,26 a 5,41 \\
\hline Umidade & $43,06 / 41,00$ & 37,77 & 43,01 & 40,48 a 43,10 & 39,78 a 47,89 & 38,15 a 42,11 \\
\hline Gordura & $38,05 / 33,98$ & 34,44 & 31,57 & - & 28,05 a 38,14 & 29,60 a 30,16 \\
\hline Proteína Total & $18,65 / 19,78$ & 19,25 & 19,51 & - & 15,9 a 22,13 & 18,9 a 24,6 \\
\hline Cinzas & $1,60 / 1,68$ & 3,99 & 2,47 & - & 1,67 a 2,52 & 1,55 a 3,13 \\
\hline EST & $56,94 / 59,00$ & $62,23 *$ & $56,99 *$ & - & 60,22 a $52,11^{*}$ & 61,85 a $57,89 *$ \\
\hline GES & $66,55 / 57,48$ & $55,27 *$ & 55,84 & - & 51,27 a $64,46^{*}$ & 50,02 a $53,45^{*}$ \\
\hline $\mathrm{Sal}(\mathrm{NaCl})$ & $0,45 / 0,66$ & - & - & - & 0,48 a 1,16 & - \\
\hline $\begin{array}{l}\text { Atividade } \\
\text { de água (aw) }\end{array}$ & $0,982 / 0,980$ & - & - & - & - & - \\
\hline *Calculado & *Calculado & & & & & \\
\hline
\end{tabular}


a influência da ação complexante dos sais fundentes utilizados no momento da fusão. Esses sequestram íons de cálcio do caseinato, induzem a entrada dos íons de sódio e tornam o caseinato mais solúvel em água. A tecnologia de produção do queijo do Marajó tipo creme assemelha-se a tecnologia de fusão de queijos processados, com a diferença de que o único sal fundente empregado é o cloreto de sódio. Objetivando uma boa fusão há de se promover a saída de cálcio da estrutura proteica que caracteriza a massa, fato este causado pelo processo fermentativo e pela adição de cloreto de sódio.

Na produção do requeijão, o processo de fusão depende da retirada do cálcio associado às proteínas, o que ocorre por meio da adição de sais fundentes e pela diminuição do $\mathrm{pH}$ (Van Dender; Gallina (2006). Desta forma, para uma perfeita fusão da massa é necessária uma diminuição do $\mathrm{pH}$ associada a ação de um sal fundente. No queijo do Marajó o sal fundente empregado é o $\mathrm{NaCl}$, com baixo poder sequestrante. Pela análise da Tabela 2 , observa-se que na época do ano que há maior fermentação da massa (na estação chuvosa, o pH médio é de 4,89) emprega-se menor quantidade de cloreto de sódio $\left(0,45 \% \mathrm{~m} \cdot \mathrm{m}^{-1}\right)$. Isso indica que quando há menor $\mathrm{pH}$ (maior fermentação) a necessidade de sal fundente $(\mathrm{NaCl})$ para o processo de fusão é menor.

$\mathrm{Na}$ estação seca, quando o pH médio é de 5,58 os queijos apresentam concentração média de cloreto de sódio de $0,66 \% \mathrm{~m} \cdot \mathrm{m}^{-1}$. Pode-se inferir a partir destes dados que a adição de cloreto de sódio no queijo do Marajó tipo creme está relacionada à capacidade de fusão da massa, sendo utilizada maior quantidade deste sal quando há a necessidade de retirada mais intensa de cálcio da massa dos queijos, o que ocorre quando o $\mathrm{pH}$ dos queijos é mais elevado. Comportamento análogo no tocante a concentração de $\mathrm{NaCl}$ variar de acordo com a época do ano também é descrito por Sousa et al. (2002).
A atividade de água não diferiu estatisticamente a $5 \%$ de probabilidade pelo teste Tukey nas estações do ano analisadas. Aquino (2011), ao estudar requeijão do Sertão fabricado na microrregião de Guanambi (BA) encontrou valores para atividade de água entre 0,96 e 0,98. Lima et al. (2011) obteve variação de 0,97 a 0,98 em queijo de manteiga. Santos et al. (2011a) verificaram atividade de água entre 0,961 a 0,977 em queijo mussarela de búfala. Segundo Santos et al. (2011a), o crescimento de bactérias que influecia na deterioração de um alimento é inibido em valores de aw inferiores a 0,90. A maioria das leveduras não cresce a aw abaixo de 0,85 e os fungos em aw abaixo de 0,70. Visto que os valores de atividade de água encontrados nos queijos propiciam grande desenvolvimento microbiano faz-se fundamental para o controle do processo produtivo o cumprimento do item 4.13.1 da Portaria número 418 da Agência de Defesa Agropecuária do Estado do Pará - ADEPARA (Pará, 2013). Neste item determina-se que a embalagem e/ou envase do queijo deve ser realizada respeitandose o que se preconiza nas Boas Práticas de Fabricação (BPF) para higiene de ambientes, equipamentos e utensílios e higiene dos funcionários responsáveis pela manipulação do queijo.

\section{Análise Microbiológica}

\section{Enumeração de indicadores higiênicos}

Os resultados da análise microbiológica foram comparados com a legislação RDC $\mathrm{n}^{\mathrm{o}} 12$ da ANVISA (ANVISA, 2001), pois as amostras foram coletadas no ponto de comercialização. Como há dois parâmetros para média umidade $(36 \%$ e $46 \%)$, optou-se pela mais rigorosa $(36 \%)$ (Tabela 4$)$.

De um modo geral, observam-se na Tabela 4, pelos percentuais, que houve uma melhoria nos resultados na estação seca, 
exceto uma discreta redução na contagem de Escherichia coli. Provavelmente, essa melhoria possa ser resultado do maior teor de $\mathrm{NaCl}$ nessa estação do ano. A análise de coliformes, embora não seja exigida pela legislação (ANVISA, 2001), é interessante, pois esses microrganismos indicadores são geralmente contaminantes ambientais que se multiplicam durante o processamento ou armazenamento. Sua alta contagem indica deficiência na qualidade higiênico-sanitária do produto. Observa-se, Tabela 4, que no período de chuva $45,45 \%$ das amostras tiveram uma contagem inferior ao limite da técnica e na seca, $72,72 \%$.

A presença de coliformes termotolerantes indica higiene deficiente. Esse grupo de microrganismo é capaz de formar biofilmes e podem contaminar os alimentos por contato com o material fecal, de humano ou animal, direta ou indireta no alimento. O valor de E.coli preconizado na legislação (ANVISA, $2001)$ é de $10^{3} \mathrm{UFC} \cdot \mathrm{g}^{-1}$. Na estação chuvosa $100 \%$ apresentaram baixa contagem, enquanto que na seca foi de $90,9 \%$. Os valores baixos na contagem tanto de coliformes e E. coli encontrados nesta pesquisa podem ser devidos, também, ao processamento. Isto porque na última etapa a massa passa por um cozimento de pelo menos $30 \mathrm{~min}$., a $80{ }^{\circ} \mathrm{C}$, temperatura que destrói esses microrganismos. Após essa etapa, alguns produtores colocam diretamente na embalagem plástica, a vácuo, ambos sem a higienização prévia das mesmas, ou em formas plásticas forradas com papel manteiga. As embalagens plásticas com o produto somente são lacradas após o resfriamento. Durante esse período, permanecem abertas no ambiente de produção, no caso do papel manteiga é vendido sem a forma. Deste modo, a contaminação

Tabela 4 - Análise microbiológica do queijo creme em duas estações do ano, chuvosa e seca

\begin{tabular}{|c|c|c|c|c|c|}
\hline \multirow[t]{2}{*}{ Indicador (UFC•g-1) } & \multicolumn{2}{|c|}{ Chuvosa } & & \multirow{2}{*}{$\begin{array}{r}\text { Seca } \\
\%\end{array}$} & \multirow{2}{*}{$\begin{array}{c}\text { Legislação } \\
\text { (ANVISA, 2001) }\end{array}$} \\
\hline & $\mathrm{n}$ & $\%$ & $\mathrm{n}$ & & \\
\hline \multicolumn{6}{|c|}{ Coliforme } \\
\hline$<10^{1}$ & 5 & 45,45 & 8 & 72,72 & \\
\hline $10^{1}$ a $10^{2}$ & 0 & 0 & 0 & 0 & Não há padrão \\
\hline$>10^{2}$ & 6 & 54,55 & 3 & 27,27 & \\
\hline \multicolumn{6}{|c|}{ Escherichia coli } \\
\hline$<10^{1}$ & 11 & 100 & 9 & 81,8 & \\
\hline $10^{1}$ a $10^{3}$ & - & - & 1 & 9,1 & \\
\hline$>10^{3}$ & - & - & 1 & 9,1 & $10^{3}$ \\
\hline $\begin{array}{l}\text { \% de acordo } \\
\text { com a Legislação }\end{array}$ & & $100 \%$ & & $90,9 \%$ & \\
\hline \multicolumn{6}{|c|}{ Staphylococus aureus } \\
\hline$<10^{1}$ & 0 & 0 & 4 & 44,44 & \\
\hline $10^{1}$ a $10^{3}$ & 2 & 18,2 & 0 & 0 & $10^{3}$ \\
\hline$>10^{3}$ & 9 & 81,8 & 5 & 55,55 & \\
\hline $\begin{array}{l}\% \text { de acordo } \\
\text { com a Legislação }\end{array}$ & & $0 \%$ & & $44,44 \%$ & \\
\hline
\end{tabular}

*n: $n^{o}$ de amostra. 
desses queijos pode ser foi associada à etapa de pós-processamento.

Estudos com queijos artesanais com diferentes processamentos encontraram alta contagem de coliformes e coliformes termotolerantes. Santos et al. (2011b), encontraram em todas as amostras de queijo coalho artesanal valor alto para contagem de coliformes e E. coli, o que indicou má qualidade higiênico-sanitária dos produtos estudados . Fernandes et al. (2011) estudaram queijos Minas artesanais e demonstraram que 100\% das amostras apresentaram contagem superior a 5,0 x $10^{3} \mathrm{NMP} \cdot \mathrm{g}^{-1}$ de coliformes e em 66,66 $\%$ coliformes termotolerantes superior ao preconizado pela legislação. Assim como, Zaffari et al. (2007) analisaram a qualidade de queijos artesanais vendido em estabelecimentos de beira de estrada no Rio Grande do Sul e encontraram que $84 \%$ dos queijos apresentaram contagens de coliformes termotolerantes acima da legislação.

Staphylococcus aureus é um microorganismo indicador que tem como habitat a nasofaringe do ser humano e pode facilmente contaminar as mãos do homem e em seguida os alimentos. Segundo a legislação brasileira (ANVISA, 2001), o valor é de $10^{3} \mathrm{UFC} \cdot \mathrm{g}^{-1}$ para queijos de média umidade (36\%). Comparando os resultados desta pesquisa 18,2 \% das amostras analisadas na estação chuvosa e 44,44 \% na estação seca estão de acordo com o parâmetro da legislação. Resultados diferentes ao encontrado por Figueiredo et al. (2011); Lourenço (1999) e Sousa et al. (2002) que não encontraram em nenhuma das amostras a presença de $S$. aureus em queijos do Marajó tipo creme. Entretanto, Aquino (2011) obteve resultado semelhante a esta pesquisa em que $46,77 \%$ estiveram dentro no padrão da legislação. Diferentemente, Ferreira et al. (2011) avaliaram a qualidade microbiológica do queijo Minas artesanal encontraram que $90 \%$ estavam com contagem acima do padrão estabelecido para $S$. aureus, concluindo que a qualidade microbiológica apresentou insatisfatória, o que representa um risco à saúde do consumidor.

\section{Contagem de aeróbios mesófilos}

Quanto aos aeróbios mesófilos, observouse que não houve alteração dentre as estações do ano a $5 \%$ de probabilidade, o qual na estação chuvosa foi 8,0 $\pm 0,97$ e na seca de 7,2 $\pm 0,99$.

Um dos produtores de queijo do Marajó utilizou sorbato de potássio, o que influenciou na contagem desse microrganismo com valores encontrados inferiores $10^{1} \mathrm{UFC} \cdot \mathrm{g}^{-1}$. Segundo o Regulamento Técnico para fixação de identidade e qualidade do requeijão (BRASIL, 1997), a concentração máxima indicada no produto final de ácido sórbico ou seus sais é de 1000 mg/ kg. Essa prática tem sido estimulada pelo trabalho de Guerra; Guerra (2003), que mostrou que o uso de sorbato de potássio em queijo de manteiga, na concentração de $0,5 \% \mathrm{~m} \cdot \mathrm{m}^{-1}$, foi eficaz para melhorar o controle do desenvolvimento fungos filamentosos e leveduras, independentemente das embalagens utilizadas.

\section{Pesquisa de patógenos}

Não foi detectada a presença de patógenos Listeria monocytogenes e Salmonella sp. no queijo do Marajó tipo creme nas duas estações do ano. Esses resultados estão de acordo com a legislação RDC n ${ }^{\circ} 12$ (ANVISA, 2001) (Tabela 6).

O resultado desta pesquisa quanto à ausência de Salmonella está de acordo com os resultados obtidos por outros trabalhos em queijo do Marajó (LOURENÇO et al., 2002; SOUSA et al., 2002, e FIGUEIREDO et al., 2011). A ausência desses patógenos nas amostras é atribuída à baixa competitividade desses microrganismos que não se sobressaem diante da microbiota diversificada existente em queijos artesanais.

Entretanto, Aquino (2011) ao estudar requeijão do Sertão, queijo artesanal fabricado 
na microrregião de Guanambi (BA) encontrou resultado diferente a esta pesquisa em que houve contaminação de L. monocytogenes ou Salmonella sp., com consequente risco à saúde.

\section{CONCLUSÕES}

A variabilidade ocorrida no $\mathrm{pH}, \%$ GES e $\mathrm{NaCl}$, entre as estações do ano, demonstra a necessidade de maior controle da produção, com o objetivo de padronização e a manutenção da identidade do produto.

Os queijos do Marajó tipo creme analisados neste trabalho apresentaram concordância com os padrões microbiológicos estabelecidos pela Legislação vigente. A etapa de cozimento da massa pode ser considerada um ponto crítico de controle microbiológico. Entretanto, não exclui o risco sanitário desse produto pela contaminação pós-processamento, principalmente, quanto à falta de higienização prévia das embalagens utilizadas.

$\mathrm{Na}$ estação chuvosa o teor GES ficou acima do preconizado pela legislação estadual (Regulamento Técnico de Produção do Queijo do Marajó), o que indica que este atributo pode ser modificado na Regulamentação visando sua adequação à realidade dos produtores de queijo da região.

\section{AGRADECIMENTOS}

Os autores agradecem aos produtores de queijos do Marajó tipo creme pelas amostras concedidas; a SAGRI, UEPA (campus de Salvaterra) e ADEPARÁ pelo apoio logístico; e a FAPEMIG, CNPq e CAPES pelo apoio financeiro do projeto.

\section{REFERÊNCIAS}

AGÊNCIA DE DEFESAAGROPECUÁRIA DO ESTADO DO PARÁ (ADEPARÁ). Portaria $\mathbf{n}^{\mathbf{0}}$ 418, de 26 de fevereiro de 2013. Aprova o Regulamento Técnico de Produção do Queijo do Marajó e dá outras providências. Belém,
2013. Disponível em: <http://www.legisweb. com.br/legislacao/?id=252036>. Acesso em: 15 ago. 2013.

AGÊNCIA NACIONAL DE VIGILÂNCIA SANITÁRIA (ANVISA). Resolução RDC n ${ }^{\circ}$, de 02 de janeiro de 2001. Aprova o Regulamento Técnico sobre Padrões Microbiológicos para Alimentos. Diário Oficial da República Federativa do Brasil, Brasília, 10 jan. 2001. Seção 1, p. 45-53.

AMARAL, F. R. et al. Qualidade do leite de búfalas: composição. Revista Brasileira de Reprodução Animal, v. 29, n. 2, p. 106-110, 2005.

ASSOCIATION OF OFFICIAL ANALYTICAL CHEMISTS (AOAC). Official Method 2001.05 - PetrifilmTM Rapid S. aureus Count Plate Method for the Rapid Enumeration of Staphylococcus aureus in Selected Foods. Gaithersburg, 2001.

AQUINO, A. A. Requeijão do Sertão fabricado na microrregião de Guanambi, Bahia: Características físico-químicas, microbiológicas e de produção. 2011. 183p. Tese (Doutorado em Ciência e Tecnologia de Alimentos) - Universidade Federal de Viçosa, Viçosa, 2011.

ARAÚJO, T. P. M. et al. Influência das estações do ano sobre a composição do leite de búfalas mantido em tanque de resfriamento. Agropecuária Científica no Semi-Árido, v. 7, n. 1, p. 01-05, 2011.

BENDELAK, M. R. Processo produtivo, características físico-químicas e microbiológicas de implantação do sistema de análise de perigos e pontos críticos de controle na produção do queijo Marajoara tipo creme. 2004. 73 f. Dissertação (Mestrado em Ciência Animal) - Universidade Federal do Pará, Belém, 2004.

BITTENCOURT, R. H. F. P M. Requeijão marajoara e queijo minas frescal produzidos 
com leite de búfalas (Bubalus bubalis) no estado do Pará. 2011. 106 f. Tese (Doutorado em Higiene Veterinária e Processamento Tecnológico de Produtos de Origem Animal) Universidade Federal Fluminense, Niterói, 2011.

BLASKOVSKY, C. et al. Avaliação primária da infra-estrutura para implementação de indústria de beneficiamento de "queijo do Marajó" no município de Cachoeira do Arari-PA. Revista Ingepro, v. 2, n. 1, 2010. Disponível em: <http:// www.ingepro.com.br/Publ_2010/Jan/175-4951-PB.pdf>. Acesso em: 20 jul. 2010.

BRASIL. Ministério da Agricultura, do Abastecimento e da Reforma Agrária. Portaria $\mathrm{n}^{\circ}$ 146, de 7 de março de 1996. Aprova os regulamentos técnicos de identidade e qualidade dos produtos lácteos. Diário Oficial da República do Brasil, Brasília, 11 mar. 1996. Seção 1, p. 3977.

BRASIL. Ministério da Agricultura e do Abastecimento. Departamento de Inspeção de Produtos de Origem Animal. Portaria no 359 de 04 de setembro de 1997. Regulamento Técnico para Fixação de Identidade e Qualidade do Requeijão Cremoso ou Requesón. Diário Oficial da República Federativa do Brasil. Brasília, 08 set. 1997 Seção 1, p. 19690.

BRASIL. Ministério da Agricultura, Pecuária e Abastecimento. Instrução Normativa $\mathrm{n}^{-} \mathbf{0} 68$, de 12 de dezembro de 2006. Oficializa os métodos analíticos oficiais físico-químicos, para controle de leite e produtos lácteos. Diário Oficial da República Federativa do Brasil, Brasília, 14 dez. 2006. Seção 1, p. 8.

FERNANDES, R. V. B. et al. Avaliação físico-química, microbiológica e microscópica do queijo artesanal comercializado em Rio Pomba-MG. Revista do Instituto de Laticínios Cândido Tostes, v. 66, n. 382, p. 21-26, 2011.

FERREIRA, R. M. et al. Pesquisa de Staphylococcus coagulase positiva em queijos minas frescal artesanal. PUBVET, v. 5, n. 5, ed. 152, art. 1021, 2011. Disponível em: <http:// www.pubvet.com.br/imagens/artigos/432011175901-carrazza1021. pdf $>$. Acesso em: 20 jul. 2010

FIGUEIREDO, E. L. et al. Queijo do "Marajó" tipo creme: parâmetros físicos-químicos e sensoriais. Revista do Instituto de Laticínios Cândido Tostes, v. 66, n. 378, p. 26-33, 2011.

GUERRA, T. M. M.; GUERRA, N. B. Influência do sorbato de potássio e do tipo de embalagem sobre a vida útil do queijo de manteiga (Requeijão do Norte). Brazilian Journal of Food Technology, v. 6, n. 2, p. 259-265, 2003.

IDE, L. P. A.; BENEDET, H. D. Contribuição ao conhecimento do queijo colonial produzido na região serrana do Estado de Santa Catarina, Brasil. Ciência e Agrotecnologia, v. 25, n. 6, p. 1351-1358, 2001.

INSTITUTO BRASILEIRO DE GEOGRAFIA E ESTATÍSTICA (IBGE). Censo Agropecuário 2006. Rio de Janeiro: IBGE, 1996. Disponível em: <http://www.ibge.gov.br>. Acesso em: 20 jul. 2010 .

INTERNATIONAL ORGANIZATION FOR STANDARDIZATION (ISO). ISO 11290-1. Microbiology of food and animal feeding stuffs - Horizontal method for the detection and enumeration of Listeria monocytogenes. Part 1: Detection Method. Geneva, 2004.

INTERNATIONAL ORGANIZATION FOR STANDARDIZATION (ISO). ISO 6579. Microbiology of food and animal feeding stuffs - Horizontal method for the detection of Salmonella sp. Geneva, 2008.

LIMA, M. C., SANTANA, R. S. M.; SANTANA, N. B. Caracterização físico-química do queijo de manteiga comercializado nos municípios de Itapetinga, Itabuna e Vitória da Conquista - BA. In: CONGRESSO BRASILEIRO DE HIGIENISTAS DE ALIMENTOS, 11., 2011, Salvador. Anais Eletrônicos... Disponível em: 
<http://www.sovergs.com.br/site/higienistas/ trabalhos/9924.pdf>. Acesso em: 20 jul. 2010.

LOURENÇO, L. F. H. et al. Análise microbiológica do requeijão marajoara elaborado no norte do Brasil. Revista Higiene Alimentar, v. 16, n. 94, p. 55-59. 2002.

LOURENÇO, L. H. F. Análise da composição química, microbiológica, sensorial e dos aromas do requeijão marajoara. 1999. 127f. Tese (Doutorado em Ciências Biológicas) Universidade Federal do Pará; Museu Paraense Emílio Goeldi; Empresa Brasileira de Pesquisa Agropecuária, Belém, 1999.

MARINO, M., MAIFRENI, M., RONDININI, G. Microbiological characterization of artisanal Montasio cheese: analysis of its indigenous lactic acid bacteria. FEMS Microbiology Letters, v. 229, n. 1, p. 133-140, 2003.

MATOS, B. C. Aspectos qualitativos do leite bubalino. PUBVET, v. 1, n. 9, ed. 9, art. 166, 2007. Disponível em: $<$ http://www.pubvet.com. br/artigos_det.asp? artigo $=166>$. Acesso em: 20 jul. 2010.

QUEIROGA, R. C. R. E. et al. Elaboração e caracterização físico-química, microbiológica e sensorial de queijo "tipo minas frescal" de leite de cabra condimentado. Revista Ciência Agronômica, v. 40, n. 3, p. 363-372, 2009.

SANTOS, C. X. et al. Caracterização físicoquímica de queijo mussarela de búfala comercializado no Sudoeste da Bahia. In: CONGRESSO BRASILEIRO DE HIGIENISTAS DE ALIMENTOS, 11., 2011, Salvador. Anais Eletrônicos... Disponível em: <http://www. sovergs.com.br/site/higienistas/trabalhos/10723. pdf $>$. Acesso em: 20 jul. 2010a.

SANTOS, G. C. F. et al. Caracterização microbiológica do requeijão do Norte comercializado em Cruz das Almas, Bahia, Brasil. In: CONGRESSO BRASILEIRO DE HIGIENISTAS DE ALIMENTOS, 11., 2011,
Salvador. Anais Eletrônicos... Disponível em: $<$ http://www.sovergs.com.br/site/higienistas/ trabalhos/10860.pdf $>$. Acesso em: 20 jul. 2010b.

SCHROEDER, G. F. et al. Effects of fat supplementation on milk production and composition by dairy cows on pasture: a review. Livestock Production Science, v. 86, n. 1, p. 1-18, 2004.

SILVA M. M. A. et al. Persistência da lactação em búfalas da raça Murrah (Bubalusbubalis) exploradas no agreste do Rio Grande do Norte. Acta Veterinária Brasilica, v. 4, n. 4, p. 286293, 2010.

SOUSA, C. et al. Avaliação microbiológica e físico-química de doce de leite e requeijão produzidos com leite de búfala na Ilha do Marajó-PA. Boletim do Centro de Pesquisa e Processamento de Alimentos, v. 20, n. 2, p. 191-202, 2002.

VIEIRA, J. N., et al. Bubalinocultura no Brasil: Short communication. PUBVET, Londrina, v. 5, n. 2, ed. 149, art. 1003, 2011. Disponível em: <http://www.pubvet.com.br/imagens/ artigos/1522011-110203-vieira1003.pdf>. Acesso em: 20 jul. 2010.

VAN DENDER, A. G. F. V., GALLINA, D. A. Princípios da fusão e propriedades dos sais fundentes. In: VAN DENDER, A. G. F. V. Requeijão cremoso e outros queijos fundidos: tecnologia de fabricação, controle do processo e aspectos de mercado. São Paulo: Fonte Comunicações, 2006. cap. 2, p. 19-37.

WEHR, H. M.; FRANK, J. F. Standard methods for the examination of dairy products. 17 th ed. Washington: American Public Health Association, 2004. 570 p.

ZAFFARI, C. B.; MELLO, J. F.; COSTA, M. Qualidade bacteriológica de queijos artesanais comercializados em estradas do litoral norte do Rio Grande do Sul, Brasil. Ciência Rural, v. 37, n. 3, p. 862-867, 2007. 